\title{
The Necessity for a Sustainable Transport System in Beirut: The Case Study of Corniche El Mazraa Arterial
}

\author{
Najib N. Georges, Mazen Omran and Mohammad Saad
}

\begin{abstract}
Corniche El Mazraa Road, one of the major arterial of Beirut - the capital city of Lebanon - is characterized by severe traffic congestion spreading over extended peak periods during the day. This is jeopardizing the transport system risking of halting the functionality of the city in addition to economic and environmental losses. The authors examined a number of mitigation measures to improve the traffic condition along Corniche El Mazraa Road. The only solution that could result in tangible improvements in the traffic conditions, in such an urban dense environment, is the introduction of a reliable public transport system.
\end{abstract}

Index Terms-Urban Environment; Traffic Congestion; Public Transport in Lebanon; Traffic Modelling.

\section{INTRODUCTION}

Beirut, the capital city of Lebanon, is home to most of governmental and private company offices. Hence, the city attracts a large portion of the population each day. Corniche El Mazraa is one of the main arterial giving access to many regions in Beirut such as Raouche, Ein El Mreise, Beirut downtown, Hamra, Achrafiye, and Cola. During peak periods, Corniche El Mazraa is suffering from severe congestions extending over many hours. Corniche El Mazraa is characterized by five successive signalized junctions, as well as commercial units on both sides of the road as illustrated in Fig. 1.

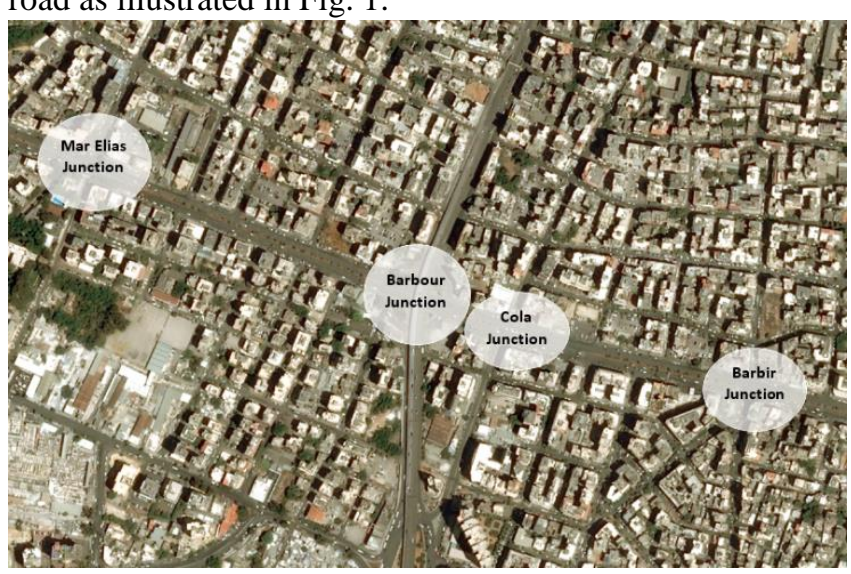

Fig. 1. Corniche El Mazraa

The authors conducted a traffic study to understand the reason behind congestion. A number of mitigation measures were proposed and tested. This paper summarizes the findings and highlights the authors' recommendation to alleviate the congestion problems.

\section{LITERATURE REVIEW}

Lebanon does not currently have a comprehensive national land transport strategy and a lack of public transport (Green Line Association). Lebanese people rely on private vehicles in their daily commutes where $90 \%$ of the Lebanese fleet consists of passenger cars, while the remaining $10 \%$ consist of buses, heavy trucks, pick-ups and motor cycles [5], [1], [4].

Although there have been numerous efforts to solve the land transport problem in Lebanon, constructing additional roads was the main policy for the Lebanese Government to tackle the ongoing and growing problem of congestion [7].

A number of authors [6] conducted detailed transport planning, traffic modelling, and economical appraisal to propose potential solutions to the traffic congestion in Beirut. The focus was mainly on Beirut Central District and its future expansion zone. Public transport was found to be one of the key solutions to alleviate the traffic problems in urban area [6].

The focus has always been on the Central Business Area of the Capital City. Therefore, in this paper, the Authors continues the work done by others [6] and examined the traffic problems and the potential solution for one of the arterial roads giving access to Beirut.

\section{CHARACTERISTICS OF THE SIGNALISED INTERSECTIONS}

The geometric characteristic of the signalized junctions along Corniche El Mazraa are described hereafter together with the signalized control.

Mar Elias Junction has three legs (leg 1and leg 2 are part of Corniche El Mazraa). Leg 1 consists of three lanes, one signal phase, and two approaches (through and right turn). Leg 2 consists of three lanes, two signals phases, and two approaches (through and left turn). Leg 3 consists of two lanes, one signal phase, and two approaches (left turn and right turn), and one channelized movement. Refer to Fig. 2.

Published on April 20, 2017.

N.N. Georges is the Chairman of Civil \& Environmental Engineering Department at the University of Balamand, Lebanon (email: najib.georges@balamand.edu.lb)

M. Omran is a visiting lecturer in the Civil \& Environmental Engineering Department at the University of Balamand, Lebanon (email: mazen_omran@hotmail.co.uk)

M. Saad is a post-graduate student in the Civil \& Environmental Engineering Department at the University of Balamand, Lebanon (email: mohammad.abed.saad@gmail.com) 


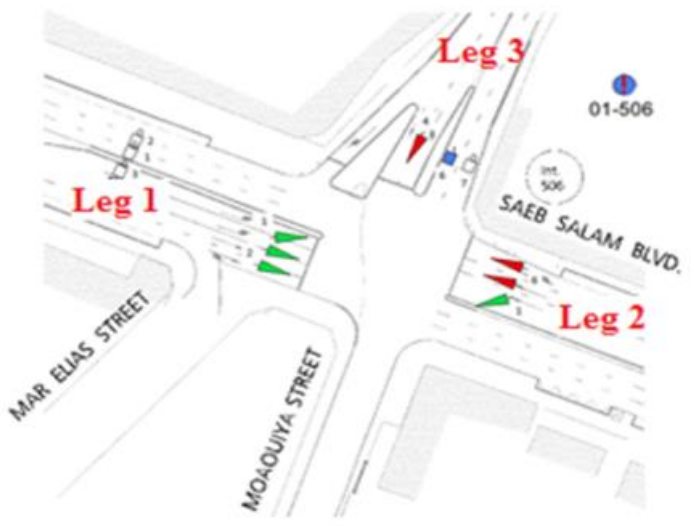

Fig. 2. Mar Elias Junction (Legs and Approaches)

Barbour Junctions has three legs (Leg 1 and Leg 3 are along Corniche El Mazraa). Leg 1 consists of three lanes, one signal phase, and two approaches (through and right turn). Leg 2 consists of three lanes, one signal phase, and three approaches (through, right turn and left turn). Leg 3 consists of three lanes, one signal phase, and one approach (through). Refer to Fig. 3.

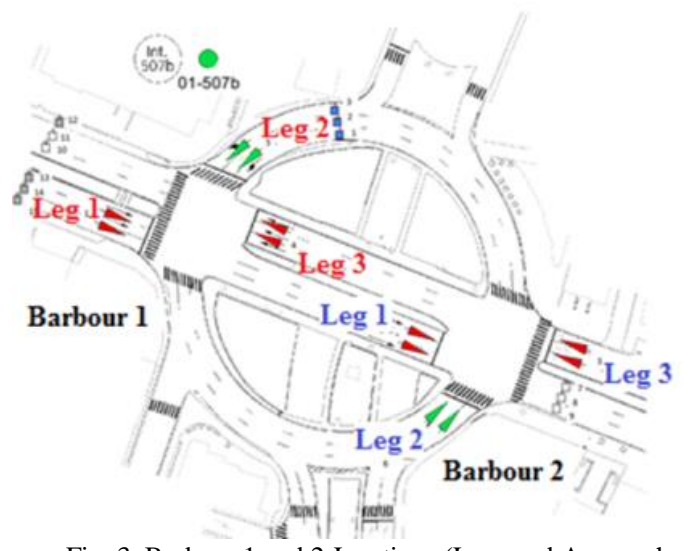

Fig. 3. Barbour 1 and 2 Junctions (Legs and Approaches)

Cola Junction has four legs (Leg1 and Leg 3 are along Corniche El Mazraa). Leg 1 consists of four lanes, two signal phases (through and left), and two approaches (through and left turn). Leg 2 consists of three lanes, one signal phase, and three approaches (through, right turn and left turn). Leg 3 consists of three lanes, one signal phase, and two approaches (through and right turn). Leg 4 consists of two lanes, one signal phase, and one approach (right turn). Refer to Fig. 4.

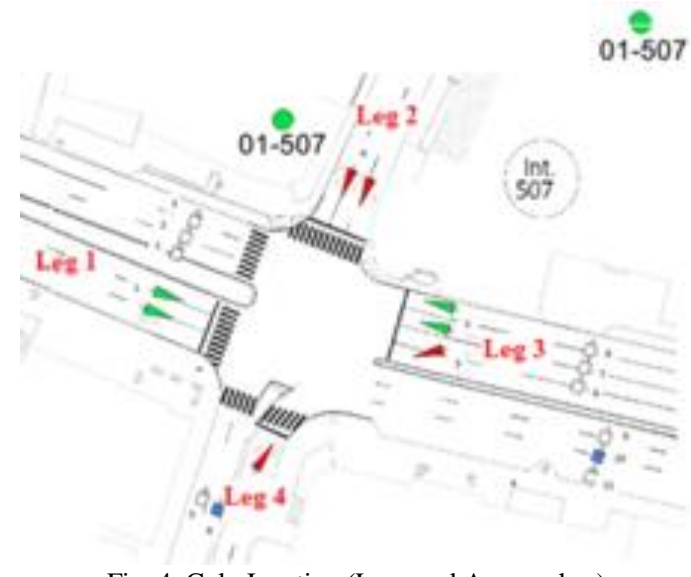

Fig. 4. Cola Junction (Legs and Approaches)
Barbir Junction has three legs (Leg 1 and Leg 2 along Corniche El Mazraa). Leg 1 consists of three lanes, one signal phase, and one approach (through). Leg 2 consists of three lanes, one signal phase, and one approach (through). Leg 3 consists of two lanes, one signal phase, and three approaches (through, right turn and left turn). Refer to Fig. 5.

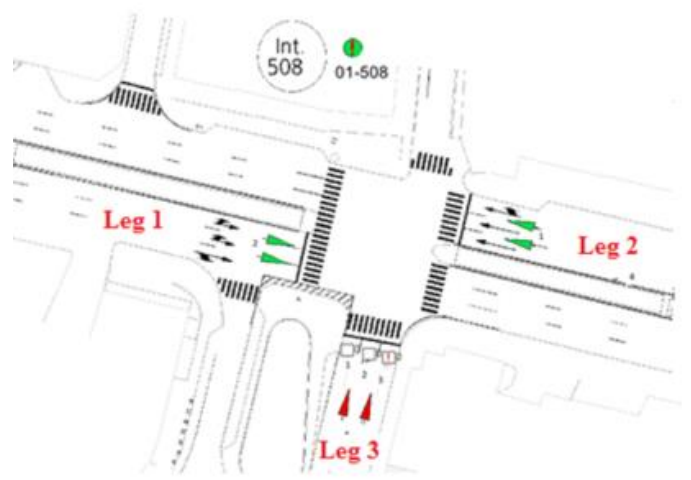

Fig. 5. Barbir Junction (Legs and Approaches)

The cycle lengths for these five junctions are summarized in Table I. The cycle length was fixed for the morning (AM) and evening (PM) peak hours.

TABLE I: EXISTING CYCLE LENGTH OF JUNCTIONS

\begin{tabular}{lc}
\hline \hline Junction & Cycle length am-pm (sec) \\
\hline Mar Elias & 120 \\
Barbour 1 & 135 \\
Barbour 2 & 135 \\
Cola & 135 \\
Barbir & 135 \\
\hline
\end{tabular}

\section{AdOPTED METHODOLOGY}

The authors conducted a classified manual traffic count for the five signalised junctions along Corniche El Mazraa. This provided the authors with the vehicles compositions, and turning movement volumes. In addition, the survey accounted for the queue length on each approach to determine the traffic demand. The details of the signalised junctions were also recorded including the green time for each phase.

The authors analysed the traffic survey data and generated a single Syncho file to model all the signalised junctions at once. The reason why a single model, including the five signalised junctions, was developed was due to the fact that these junctions are not independent since one will have an impact on the other. The Synchro software is considered as an international tool to model the current condition (base case scenario) and test mitigation measures.

A number of mitigation measures were proposed and modelled. Traffic key performance indices (KPIs) were identified for the appraisal of the proposed options.

\section{TRAFFIC SURVEY}

The traffic survey was conducted on a typical weekday. The survey was done for two periods of the day, where peak volumes occur, morning (AM) peak period and evening (PM) peak period. The morning period was from 6:00 am till 9:00 am. The evening period was from 5:00 pm till 8:00 
pm. In these two periods, severe congestion occurs because people are going to their works, schools, and universities and coming back.

The vehicles were classified into three categories: cars, vans and pick-ups, and busses (trucks are prohibited from using Corniche El Mazraa during the peak hours). The counts were manually conducted and aggregated every 5 minutes per movement at each junction. After counting the data every 5 minutes per movement at each junction, the data was compiled per 15 minutes. This data was to determine the peak hour within the peak period. The peak hour is the hour where the highest traffic demand was recorded.

The peak hour was determined per approach, per junction, and a unified one for all of the five junctions. Table II illustrates the data for Mar Elias junction as an example.

TABLE II: PEAK HOUR AT MAR ELIAS JUNCTION (AM PEAK)

\begin{tabular}{ccccc}
\hline \hline Time & Leg 1 & Leg 2 & Leg 3 & Total \\
\hline $7: 30-8: 30$ & 1,575 & 1,840 & 673 & 4,088 \\
$7: 45-8: 45$ & 1,581 & 1,769 & 730 & 4,080 \\
\hline \hline
\end{tabular}

The traffic demand is not uniformly distributed along the peak hour, therefore the authors adopted a surge factor for a 15-minute period to reflect this. The relationship between the peak 15-minutes flow rate and the full hourly volume is given by the peak-hour factor (PHF) as shown in (1)

PHF $=\frac{\text { Total volume per peak hour }}{4 \times \text { volume during peak } 15 \text { min within peak hour }}$

Table III provides an illustrative example showing the traffic volume per 15-minute interval and how these change after applying the PHF factor. TABLE III: PEAK HOUR FACTOR (PHF)

\begin{tabular}{|c|c|c|c|}
\hline Time & Volume & PHF & Volume/PHF \\
\hline $7: 15-7: 30$ & 356 & 0.893 & 399 \\
\hline $7: 30-7: 45$ & 392 & 0.893 & 439 \\
\hline $7: 45-8: 00$ & 297 & 0.893 & 333 \\
\hline 8:00-8:15 & 355 & 0.893 & 398 \\
\hline Total & 1,400 & & 1,568 \\
\hline
\end{tabular}

The traffic survey data was analyzed to determine the traffic composition for each turning movement during the unified peak hours. Table 4 shows an illustrative example for the Cola Junction.

TABLE IV: PERCENTAGE OF VEHICLES AT COLA JUNCTIONS LEG 3 C(CAR) B(BUS) P(PICK-UP) V (VAN)

\begin{tabular}{|l|l|l|l|l|l|l|l|l|}
\hline \hline \multicolumn{3}{c|}{ Straight } & \multicolumn{3}{c|}{ Left } & \multicolumn{3}{c}{ U turn } \\
\hline $\mathrm{C}$ & $\mathrm{B}$ & $\mathrm{P} / \mathrm{V}$ & $\mathrm{C}$ & $\mathrm{B}$ & $\mathrm{P} / \mathrm{V}$ & $\mathrm{C}$ & $\mathrm{B}$ & $\mathrm{P} / \mathrm{V}$ \\
\hline 95.7 & 1.9 & 2.2 & 84.7 & 3.4 & 11.8 & 76.8 & 10.0 & 13.1 \\
\hline \hline
\end{tabular}

The traffic demand is the total volume of vehicles on the junction. It is obtained by compiling the number of vehicles crossing the intersection and the number of vehicles stopping on the red light (queue).

The traffic analysis showed that the peak hours occurred between 7:15am and 8:15am for the AM peak hour, and from 5:00pm and 6pm for the PM peak hour.

\section{TrafFic Modelling And Mitigation MeAsures}

The input data needed by the Synchro software are the traffic volumes, turning movements, percentage of heavy vehicles, peak hour factor, number of lanes, width of lanes, design speed and cycle length which includes the green time, yellow time and red time.
This software generates the queue length, average vehicle delay, and intersection level of service (LOS) [2]. The LOS thresholds values are provided in Table $\mathrm{V}$.

TABLE V: LEVEL OF SERVICE CRITERIA (HCM 2010)

\begin{tabular}{lc}
\hline \hline Control Delay Per Vehicle $(\mathrm{sec})$ & Level Of Service \\
\hline$\leq 10$ & $\mathrm{~A}$ \\
$10>$ and $\leq 20$ & $\mathrm{~B}$ \\
$20>$ and $\leq 35$ & $\mathrm{C}$ \\
$35>$ and $\leq 55$ & $\mathrm{D}$ \\
$55>$ and $\leq 80$ & $\mathrm{E}$ \\
$>80$ & $\mathrm{~F}$ \\
\hline \hline
\end{tabular}

To account for the presence of on street shops and local roads, dummy links were introduced for the purpose of balancing the volumes over the intersections. In addition, the authors calibrated the model in such a way that the calculated queue length on each approach matched the observed one from the traffic survey.

The values of LOS for isolated junctions are provided in Tables VI and VII, and for the full model in Tables VIII and IX. The reason for this modelling task was to demonstrate the impact of one junction of the other.

TABLE VI: RESULTS FOR ISOLATED JUNCTIONS (AM PEAK HOUR)

\begin{tabular}{|c|c|c|}
\hline Junction & Delay (sec) & LOS \\
\hline Mar Elias & 291 & $\mathrm{~F}$ \\
\hline Barbour 1 & 52.4 & $\mathrm{D}$ \\
\hline Barbour 2 & 63.6 & $\mathrm{E}$ \\
\hline Cola & 185 & $\mathrm{~F}$ \\
\hline Barbir & 23.3 & $\mathrm{C}$ \\
\hline \multicolumn{3}{|c|}{ TABLE VII: RESULTS FOR ISOLATED JUNCTIONS (PM PEAK HOUR } \\
\hline Junction & Delay (sec) & LOS \\
\hline Mar Elias & 31.4 & $\mathrm{C}$ \\
\hline Barbour 1 & 71.8 & $\mathrm{E}$ \\
\hline Barbour 2 & 29.2 & $\mathrm{C}$ \\
\hline Cola & 150.9 & $\mathrm{~F}$ \\
\hline Barbir & 18.1 & $\mathrm{~B}$ \\
\hline \multicolumn{3}{|c|}{ TABLE VIII: RESULTS FOR COMBINED MODEL (AM PEAK HOUR } \\
\hline Junction & Delay (sec) & LOS \\
\hline Mar Elias & 77.3 & $\mathrm{E}$ \\
\hline Barbour 1 & 87.2 & $\mathrm{~F}$ \\
\hline Barbour 2 & 116 & $\mathrm{~F}$ \\
\hline Cola & 204.2 & $\mathrm{~F}$ \\
\hline Barbir & 20.4 & $\mathrm{C}$ \\
\hline \multicolumn{3}{|c|}{ TABLE IX: RESULTS FOR COMBINED MODEL (PM PEAK HOUR) } \\
\hline Junction & Delay (sec) & LOS \\
\hline Mar Elias & 31.9 & $\mathrm{C}$ \\
\hline Barbour 1 & 42.1 & $\mathrm{D}$ \\
\hline Barbour 2 & 363.8 & $\mathrm{~F}$ \\
\hline Cola & 398.5 & $\mathrm{~F}$ \\
\hline Barbir & 13.9 & $\mathrm{~B}$ \\
\hline
\end{tabular}

The comparison of Table VI to IX shows that in general, the Combined Model resulted in worse results due to the impact of one junction on the other. Therefore, for the mitigation measure, the Combined Model was adopted.

A number of mitigation measures were proposed in an attempt to alleviate the congestion along Corniche El Mazraa. Nine mitigation measures were proposed and tested. The mitigation measures consisted of the following changes when compared to the base model (current condition):

1) Actuated Signals - The types of signals for the base model were changed from pre-timed signals to actuated signals (signal optimization) 
2) Public Transport - A 20\% public transport was proposed which can reduce the volume of vehicles $20 \%$ ( $20 \%$ is the targeted public transport share in Beirut).

3) Actuated Signals, and Public Transport - This measure is a combination of the first two measures

4) Additional Lane per Direction - The parking lanes from the edges of the street were removed to increase the number of lanes (geometric change). These parking lanes are used by vehicles going into the commercial shops. As a result of this mitigation measure, parking should be provided on the back streets

5) Additional Lane, Public Transport, and Actuated Signals - Identical to Mitigation Measure 4 but the signals were changed from pre-timed to actuated

6) Tunnel - In this measure, a tunnel which starts between Mar Elias Junction and Barbour 1 Junction, and ends before Barbir Junction was proposed. This tunnel is a four lane divided tunnel (two lanes in each direction). This measure can be considered as a geometric change and it alleviates the signalized junctions from the heavy through traffic along Corniche El Mazraa

7) Tunnel and Public Transport - This is identical to Mitigation Measure 6 with a $20 \%$ reduction in traffic volumes due to introducing public transport

8) Tunnel and Actual Signals - In addition to the proposed tunnel, the signal type of intersection was changed from pre-timed to actuated

9) Tunnel, Public Transport, and Actuated Signals - A tunnel, 20\% public transport, and actuated signals system was proposed and this mitigation measure has proved to be the most efficient for this situation

Table $\mathrm{X}$ provides a comparison of the level of service results for the AM and PM peak hours.

TABLE X: APPRAISAL OF THE PROPOSED Mitigation MEASURES

\begin{tabular}{|c|c|c|c|c|c|}
\hline \multirow[b]{2}{*}{ Scenario } & \multicolumn{5}{|c|}{ Level of service (AM/PM) } \\
\hline & $\begin{array}{l}\text { Mar } \\
\text { Elias }\end{array}$ & Barbour 1 & $\begin{array}{c}\text { Barbour } \\
2\end{array}$ & Cola & Barbir \\
\hline Base Model & $\mathrm{E} / \mathrm{C}$ & F/D & $\mathrm{F} / \mathrm{F}$ & $\mathrm{F} / \mathrm{F}$ & $\mathrm{C} / \mathrm{B}$ \\
\hline Mitigation 2 & $\mathrm{E} / \mathrm{C}$ & $\mathrm{F} / \mathrm{D}$ & $\mathrm{F} / \mathrm{F}$ & $\mathrm{F} / \mathrm{F}$ & $\mathrm{C} / \mathrm{B}$ \\
\hline Mitigation & $\mathrm{C} / \mathrm{C}$ & $\mathrm{C} / \mathrm{C}$ & $\mathrm{C} / \mathrm{C}$ & $\mathrm{F} / \mathrm{F}$ & $\mathrm{B} / \mathrm{B}$ \\
\hline Mitigation 3 & $\mathrm{C} / \mathrm{B}$ & $\mathrm{C} / \mathrm{B}$ & $\mathrm{C} / \mathrm{E}$ & $\mathrm{F} / \mathrm{E}$ & $\mathrm{B} / \mathrm{A}$ \\
\hline Mitigation 4 & $\mathrm{C} / \mathrm{C}$ & $\mathrm{D} / \mathrm{C}$ & $\mathrm{E} / \mathrm{E}$ & $\mathrm{F} / \mathrm{F}$ & $\mathrm{B} / \mathrm{B}$ \\
\hline Mitigation 5 & $\mathrm{C} / \mathrm{C}$ & $\mathrm{D} / \mathrm{D}$ & $\mathrm{E} / \mathrm{D}$ & $\mathrm{F} / \mathrm{E}$ & $\mathrm{B} / \mathrm{B}$ \\
\hline Mitigation 6 & $\mathrm{C} / \mathrm{B}$ & $\mathrm{B} / \mathrm{B}$ & $\mathrm{D} / \mathrm{C}$ & $\mathrm{C} / \mathrm{C}$ & $\mathrm{B} / \mathrm{B}$ \\
\hline Mitigation 7 & $\mathrm{C} / \mathrm{B}$ & $\mathrm{B} / \mathrm{B}$ & $\mathrm{C} / \mathrm{A}$ & $\mathrm{B} / \mathrm{C}$ & $\mathrm{B} / \mathrm{B}$ \\
\hline Mitigation 8 & $\mathrm{C} / \mathrm{B}$ & $\mathrm{B} / \mathrm{B}$ & $\mathrm{C} / \mathrm{B}$ & $\mathrm{B} / \mathrm{C}$ & $\mathrm{B} / \mathrm{B}$ \\
\hline Mitigation 9 & $\mathrm{C} / \mathrm{B}$ & $\mathrm{B} / \mathrm{B}$ & $\mathrm{C} / \mathrm{A}$ & $\mathrm{B} / \mathrm{B}$ & $\mathrm{B} / \mathrm{B}$ \\
\hline
\end{tabular}

Table $\mathrm{X}$ shows that the improvements in the level of service (compared with the base model scenario) varies depending on the combination of the proposed mitigation measures. Without the proposed tunnel, Mitigation Measure 5 (additional lane, public transport, and actuated signals) provided the best results however, the Cola junction will remain the bottle neck causing traffic congestion along Corniche El Mazraa. The tunnel, with public transport and actuated signals (Mitigation Measure 9) provide the best option when compared with all the proposed ones.

Table XI and Table XII provide the encountered delay at each one of the five junctions along Corniche El Mazraa for Mitigation Measure 9. Fig. 6 illustrated the stretch of the required tunnel.
TABLE XI: LeVel of SERVICE - Mitigation MEAsure 9 - AM PEAK HOUR

\begin{tabular}{lcl}
\hline Junction & LOS & Delay (s) \\
\hline Mar Elias & C & 25.4 \\
Barbour 1 & B & 13.6 \\
Barbour 2 & C & 22.1 \\
Cola & B & 18.7 \\
Barbir & B & 13.3 \\
\hline \hline TABLE XII: LEVEL OF SERVICE & - MITIGATION MEASURE & $9-$ AM PEAK \\
HouR & & \\
\hline \hline Junction & LOS & Delay (s) \\
\hline Mar Elias & B & 14.3 \\
Barbour 1 & B & 10.9 \\
Barbour 2 & A & 9.0 \\
Cola & B & 18.5 \\
Barbir & B & 10.5 \\
\hline \hline
\end{tabular}

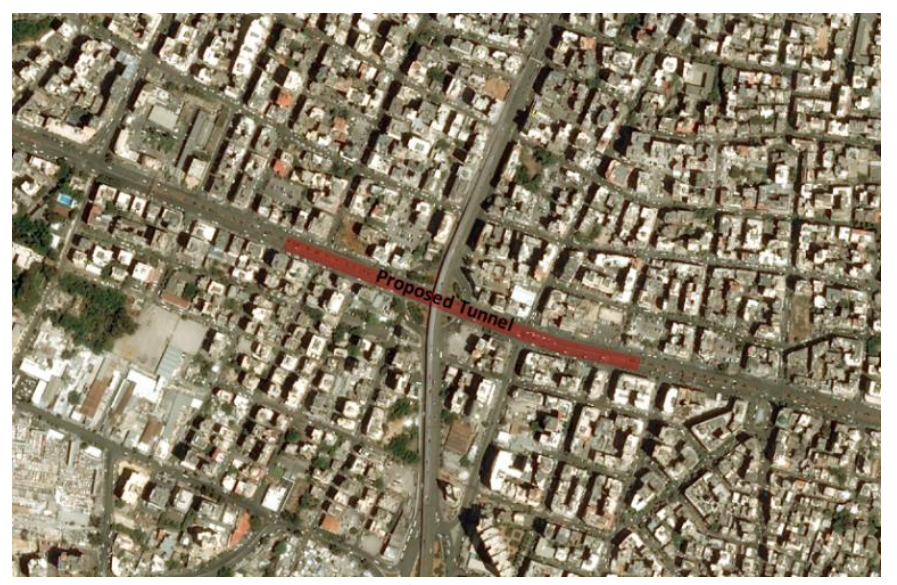

Fig. 6. Stretch of the Proposed Tunnel

Due to the actuated operation of the signals, a cycle length of $100 \mathrm{sec}$ will be required for the AM peak hour, and $60 \mathrm{sec}$ for the PM peak hour.

\section{CONCLUSION AND RECOMMENDATIONS}

Corniche El Mazraa is located in a dense urban environment where traffic congestion is severe during extended peak periods. The authors liaised the congestion problem to the high traffic volumes and the independent operation of the signalized junctions where the level of service reach F for both of the AM and PM peak hours.

A number of mitigation measures were proposed including soft (actuated measures and public transport) and hard mitigation measures (public transport, additional lanes, and tunnel). The soft measure improved the current traffic conditions to an acceptable level, however, tunnels will be needed to meet the future growth of traffic. The authors understand the cost associated with additional infrastructure, therefore public transport should be encouraged and enforced.

Both the soft and hard measures require the introduction of a sustainable and reliable transport system. This is considered the key mitigation measure for traffic congestion problems in dense urban areas.

\section{ACKNOWLEDGMENT}

The authors would like to express gratitude to Ayman Ramadan and Ghaleb Damaj who were of great assistance in 
writing this paper and in data collection.

\section{REFERENCES}

[1] F. Chaaban F, I. Kaysi, R. Chedid, 'Contribution of Transportation to GHG Emissions - Case Study of Lebanon”, World Resource Review. Vol. 12, no. 2, 2000

[2] HCM2010, "Highway Capacity Manual", Washington, DC., 2010

[3] D.Husch, J. Albeck, "Synchro Studio 7 [Computer software]", Sugar Land, TX: Trafficware, 2006

[4] Lebanese Ministry of the Environment, "Lebanon 2001 State of the Environment Report", ECODIT Liban, 2002
[5] A. Mourtada, "The management body for land transport, the passenger transport sector", Conference on the land transport sector in Lebanon. The Lebanese Parliament and UNDP, 2002

[6] M. Omran, J. Ojeil, F. Fawaz, "Economic Impact of Adopting a Sustainable Transport System in Beirut", Climate Change and Environment in the Arab World Program, Sustainable Transport Series, American University of Beirut, 2015

[7] H. Sbayti, M. El-Fadel, I. Kaysi I, H. Baaj, "Automotive Emissions in Developing Countries: Traffic Management and Technological Control Measures", Department of Civil and Environmental Engineering, American University of Beirut. Beirut, Lebanon, 2002 